OPEN ACCESS

Edited by:

Omer Frenkel,

Agricultural Research Organization

(ARO), Israe

Reviewed by:

Eva Maria Zyprian,

Institut für Rebenzüchtung, Julius Kühn-Institut, Germany

Marisa Maia,

University of Lisbon, Portugal

*Correspondence:

Susana Boso

susanab@mbg.csic.es

Specialty section:

This article was submitted to

Plant Pathogen Interactions,

a section of the journal

Frontiers in Plant Science

Received: 01 March 2021

Accepted: 22 November 2021

Published: 10 December 2021

Citation:

Ruiz-García L, Gago P,

Martínez-Mora C, Santiago JL,

Fernádez-López DJ, Martínez MC and

Boso S (2021) Evaluation

and Pre-selection of New Grapevine

Genotypes Resistant to Downy

and Powdery Mildew, Obtained by

Cross-Breeding Programs in Spain.

Front. Plant Sci. 12:674510.

doi: $10.3389 /$ fp/s.2021.674510

\section{Evaluation and Pre-selection of New Grapevine Genotypes Resistant to Downy and Powdery Mildew, Obtained by Cross-Breeding Programs in Spain}

\author{
Leonor Ruiz-García', Pilar Gago², Celia Martínez-Mora', José Luis Santiago², \\ Diego J. Fernádez-López ${ }^{1}$, María del Carmen Martínez ${ }^{2}$ and Susana Boso ${ }^{2 *}$ \\ ' Department of Biotechnology, Genomics and Plant Breeding, Instituto Murciano de Investigación y Desarrollo Agrario y \\ Alimentario, Murcia, Spain, ${ }^{2}$ Department of Viticulture and Forestry, Misión Biológica de Galicia (Consejo Superior \\ de Investigaciones Científicas, CSIC), Salcedo, Spain
}

The need to develop an environmentally friendly, sustainable viticulture model has led to numerous grapevine improvement programmes aiming to increase resistance to downy and powdery mildew. The success of such programmes relies on the availability of protocols that can quantify the resistance/susceptibility of new genotypes, and on the existence of molecular markers of resistance loci that can aid in the selection process. The present work assesses the degree of phenotypic resistance/susceptibility to downy and powdery mildew of 28 new genotypes obtained from crosses between "Monastrell" and "Regent." Three genotypes showed strong combined resistance, making them good candidates for future crosses with other sources of resistance to these diseases (pyramiding). In general, laboratory and glasshouse assessments of resistance at the phenotype level agreed with the resistance expected from the presence of resistanceassociated alleles of simple sequence repeat (SSR) markers for the loci Rpv3 and Ren3 (inherited from "Regent"), confirming their usefulness as indicators of likely resistance to downy and powdery mildew, respectively, particularly so for downy mildew.

Keywords: downy mildew, powdery mildew, resistance, grapevine, marker-assisted breeding, Vitis

\section{INTRODUCTION}

Downy and powdery mildew (caused by Plasmopara viticola and Erysiphe necator, respectively) are some of the most important diseases of grapevines worldwide. Both reduce crop yield and quality leading to economic losses. Vitis vinifera is highly susceptible to both, while American and Asian vine species are much more resistant, perhaps due to their co-evolution with the causal pathogens (Armijo et al., 2016). The most efficient way to deal with them is chemical control, but this can have a negative biological and ecological impact; sustainable and environmentally friendly viticulture requires such treatment be reduced. Since the discovery of sources of resistance to these pathogens, many grapevine genetic improvement programmes around the world have tried to produce quality grapevine hybrids carrying the resistance genes of wild American vine species - but this has not been easy (Töpfer et al., 2011; Villano and Aversano, 2020). We still lack knowledge on the molecular 
bases of such resistance, and several backcrosses are often required before a hybrid of sufficient winemaking quality and lasting disease resistance is obtained. Such programmes have involved the use of American vine species, e.g., Vitis riparia, Vitis rupestris, Muscadinia rotundifolia, Vitis cinerea, etc., or species from the Far East, such as Vitis piasezkii, Vitis amurensis, Vitis romanetii, or Vitis vinifera Kishmish vatkana (Merdinoglu et al., 2018; Maul and Töpfer, 2019). These show either partial resistance, or, in the case of $M$. rotundifolia and $V$. piasezkii, complete resistance (Wan et al., 2007; Bellin et al., 2009; Casagrande et al., 2011; Gessler et al., 2011). Many studies have also tried to compare the degree of resistance to P. viticola and E. necator of the hybrids produced in different improvement programmes (Hoffmann et al., 2008; Kozma et al., 2009; Vezzulli et al., 2017, 2019; Bove et al., 2020; Possamai et al., 2020).

To date, 31 grapevine genomic regions have been associated with resistance to downy mildew (Rpv loci) and 13 with resistance to powdery mildew (Run loci and Ren loci) according to the table of loci for traits in grapevine relevant for breeding and genetics (update April 30, 2021 ${ }^{1}$ ). The availability of markers that reveal the presence of these loci could allow for the marker-assisted selection (MAS) of likely resistant genotypes (Eibach et al., 2007; Kozma et al., 2009; Vezzulli et al., 2019; Zini et al., 2019). The resistance actually shown by a genotype can then be tested in the field and under controlled laboratory/glasshouse conditions following established protocols (Brown et al., 1999; Boso et al., 2006, 2010, 2014; Prajongjai et al., 2014). New material resistant to both diseases coming out of improvement programmes includes the variety "Regent." Obtained at the Julius-Kühn Institute in Germany, its pedigree includes American vines carrying Ren3, Ren9, Rpv3, Rpv4, and Rpv11 (Fischer et al., 2004; Welter et al., 2007; Zendler et al., 2017).

The aim of the present work was to assess the degree of phenotypic resistance/susceptibility to downy and powdery mildew of 28 "Monastrell" $\times$ "Regent" hybrids selected for their carriage of resistance-associated alleles of simple sequence repeat (SSR) markers for the loci Rpv3 and Ren3, and thus being likely resistant to these diseases. The results allow for the selection of genotypes that could be used in future crosses with other sources of resistance to downy and powdery mildew (pyramiding).

\section{MATERIALS AND METHODS}

\section{Plant Material}

The study material included 28 new genotypes obtained by crosses in 2012 (Ruiz-García et al., 2014) between "Monastrell" (susceptible to downy mildew and with medium resistance to powdery mildew) and "Regent" which carries the loci Rpv3 and Ren3 (Fischer et al., 2004; Welter et al., 2007).

The identity of the parentals and of the 28 genotypes produced from them was performed by PCR amplification

${ }^{1}$ https://www.vivc.de/ of nine SSR markers registered in the NCBI database ${ }^{2}$ (Supplementary Table 1).

\section{Amplification of Resistance-Associated Molecular Markers of Rpv3 and Ren3}

The resistance-associated molecular markers of $R p v 3$ and Ren3 used in this work and their sequences are shown in Supplementary Table 2. PCR analyses to detect the presence of the SSR alleles-associated to resistance were performed according to Bayo-Canha et al. (2019). "Monastrell" and "Regent" were used as negative and positive controls, respectively.

\section{Resistance to Downy and Powdery Mildew}

Resistance to downy mildew was examined using the leaf disc test (laboratory conditions) (Rumbolz et al., 2002). Susceptibility to powdery mildew was examined using the (modified) method of Wang et al. (1995) (glasshouse conditions). Resistance to both diseases was also recorded via the use of official OIV descriptors (Organisation Internationale de la Vigne et du Vin [OIV], 2009), with small modifications. All tests were performed in triplicate. "Monastrell" and "Regent" were used as controls for the resistance assays.

\section{Plant Material Used}

At least 60 cuttings with 2-3 buds were taken in January from each of the field-grown genotypes. These were disinfected, dipped in paraffin wax and preserved in a cold chamber for at least 8 weeks to encourage later sprouting in a glasshouse under controlled conditions of temperature and humidity $\left(25^{\circ} \mathrm{C}\right.$, $\mathrm{RH}>95 \%, 16 \mathrm{~h}$ white light at 400-700 $\mathrm{nm}$ and $8 \mathrm{~h}$ darkness). Thirty plants of each genotype were used to examine resistance to either disease.

\section{Pathogen Material}

Plasmopara viticola and Erysiphe necator were obtained from plants naturally infected in the experimental vineyards of the Misión Biológica de Galicia (MBG-CSIC). For P. viticola, sporangia for inocula were propagated following the method of Rumbolz et al. (2002). For E. necator, no propagation was needed since plenty of conidia were already available on infected 'Castañal' host plants. To prepare the inoculum, fresh conidia were collected using a small paintbrush, placed in centrifuge tubes, and diluted with $50 \mathrm{ml}$ of distilled water with $0.05 \%$ Tween 20, thus obtaining a final concentration of 50,000 conidia $\mathrm{ml}^{-1}$.

\section{Resistance to Downy Mildew (Laboratory Leaf Disc Tests)}

The 5th or 6th unfurled leaf on a green shoot of each of the 30 plants per genotype grown in the glasshouse (see above) was detached. Leaf discs were prepared and incubated according to Rumbolz et al. (2002). Disease incidence and disease severity were visually analysed as independent variables at 5 days postinoculation (dpi) according to the method of Boso et al. (2014).

\footnotetext{
${ }^{2}$ https://www.ncbi.nlm.nih.gov/
} 
Resistance to Powdery Mildew (Glasshouse Conditions)

Ten plants per genotype were challenged on their adaxial leaf surfaces by spraying with the prepared conidial suspension. They were then incubated for $5-6$ days at $24^{\circ} \mathrm{C}$, at an $\mathrm{RH}$ of $<55 \%$, and under long day conditions (white light at $400-700 \mathrm{~nm}, 16 \mathrm{~h}$ light and $8 \mathrm{~h}$ dark). At 5-6 dpi, disease incidence was calculated as the number of leaves with sporulating lesions per total number of leaves per plant, and disease severity as the percentage of leaf area showing symptoms of sporulation.

Disease Assessment Using Organisation Internationale de la Vigne et du Vin Descriptors

Descriptors recommended by the OIV [OIV452-1 for downy mildew (leaf discs inoculated with $P$. viticola sporangia) and OIV455-1 for powdery mildew (leaf in glasshouse inoculated with E. necator)] (Organisation Internationale de la Vigne et du Vin [OIV], 2009). Different scores for resistance to downy and powdery mildew are available in Supplementary Figures 1, 2.

\section{Statistical Analysis}

The differences between the studied variables were analysed by ANOVA using the fixed effects model $(p<0.001)$. Following ANOVA, significant $F$ values were subjected to comparison using Fisher's protected least significant difference (LSD) test $(p<0.05)$. The association between phenotypic resistance and that expected from the possession of resistance-associated alleles of the SSR markers was determined via the Chi squared test. All calculations were made using SAS V8.1 software (SAS Institute, Cary, NC; 2000).

\section{RESULTS}

\section{Presence of Resistance-Associated Simple Sequence Repeat Alleles Rpv3}

Of the 28 genotypes examined, 18 were positive for the resistance-associated SSR allele UDV305_299 bp, 18 for UDV737_279 bp, 18 for UDV108_238 bp, and 18 for GF188_392 bp (Supplementary Table 3). The 18 genotypes that carried all four alleles were deemed likely resistant to downy mildew.

\section{Ren3}

Of the 28 genotypes examined, 20 were positive for the resistanceassociated SSR allele GF15-42_199 bp, 19 for GF15-28_341 bp, 21 for GF15-30_446 bp, and 21 for VChr15CenGen06_283 bp (Supplementary Table 3). The 19 genotypes that carried all these alleles were deemed likely resistant to powdery mildew.

Nine genotypes (genotypes 4_136, 5_022, 5_033, 5_107, $6 \_018,6 \_025,6 \_046,6 \_080$, and 6_125) carried the resistanceassociated SSR alleles for both Rpv3 and Ren3 (Supplementary Table 3), and were deemed likely resistant to both diseases.

\section{Phenotypic Resistance Downy Mildew}

"Monastrell" showed high disease incidence (100\%) and severity scores (58\%), while "Regent" showed medium incidence (54\%) and low severity (8\%) scores. With respect to descriptor code OIV 452-1, "Monastrell" showed a score of 1 , and "Regent" a score of 5 (Table 1). Among the 27 new genotypes tested, disease incidence ranged between 9 and $100 \%$, and disease severity between 5 and $67 \%$. With respect to the same descriptor code, and taking incidence and severity into account, six genotypes showed a resistance score of 9 , six a score of 7 , four a score of 5 , one a score of 3 , and 10 a score of 1 . It should be noted that 12 genotypes (3_032, 3_082, 4_032, 4_063, 4_082, 5_022, 5_033, 5_060, 5_078, 5_107, 6_046, and 6_080) were transgressive with respect to the resistance donor "Regent" (OIV $=5$ ), and showed greater resistance (OIV $=9$ and 7$)$. "Monastrell" and genotypes 3_094, 4_005, 4_037, 4_011, 4_136, 3_070, 3_073, 4_001, and 3_052 were the least resistant of all; they showed significantly higher incidence and severity scores (Table 1 and Supplementary Figure 3). Genotype 6_080 was significantly more resistant than the rest, with low severity and incidence scores (Figure 1a). Genotypes 5_078, 4_082, 4_063, 5_022, and 5_107 showed somewhat less resistance, with slightly higher incidence values but similar severity values. The remaining genotypes showed medium resistance, with intermediate disease incidence and severity scores.

\section{Powdery Mildew}

"Monastrell" showed high incidence (50\%) and severity (65\%) scores, while "Regent" showed scores of only 25 and $8 \%$, respectively $(p<0.01)$. With respect to descriptor code OIV 455-1, "Monastrell" had a score of 5, while "Regent" scored 9. For the 28 new genotypes tested, disease incidence ranged between 0 and $53 \%$, while severity ranged from 0 to $65 \%$. With respect to the same descriptor code, and taking incidence and severity into account, 22 genotypes showed a resistance score of 9 , two a score of 7 , three a score of 5 , and one a score of 3 (Table 1). With respect to descriptor code OIV 455-1, genotype 5_060 showed transgressive segregation and less strong resistance (OIV $=3$ ) than "Monastrell" (OIV = 5). Genotype 5_060 and "Monastrell" showed significantly higher incidence and severity scores compared to the rest (Table 1; Figure 1b; Supplementary Figure 3). Genotypes 3_082, 4_063 and 4_124 showed medium resistance (lower severity score). "Regent" grouped with the genotypes showing the lowest incidence and severity values (Table 1 and Supplementary Figure 3); genotypes 3_058 and 5_107 showed no symptoms of disease at all (Table 1).

\section{Combined Resistance to Both Diseases}

Genotypes 6_080, 5_107 and 4_082 showed the greatest combined resistance to both diseases, with incidence and severity values much lower than those shown even by "Regent" (Table 1).

\section{Association Between Phenotypic Resistance and Possession of Resistance-Associated Simple Sequence Repeat Alleles Rpv3}

Supplementary Table 4 shows the association between possession of the SSR alleles UDV305_299 bp, UDV737_279 bp, 
TABLE 1 | Mean disease severity (DS), disease incidence (DI), OIV scores, and resistance genotype for downy mildew and powdery mildew.

\begin{tabular}{|c|c|c|c|c|c|c|c|c|c|c|c|}
\hline \multirow[b]{2}{*}{ Vine material } & \multicolumn{5}{|c|}{ Phenotype post-inoculation with downy mildew } & \multicolumn{5}{|c|}{ Phenotype post-inoculation with powdery mildew } & \multirow[b]{2}{*}{ *Genotype } \\
\hline & DS (\%) & S.D. & DI (\%) & S.D. & OIV (452-1) & DS (\%) & S.D. & DI (\%) & S.D. & OIV (455-1) & \\
\hline Monastrell & $58.3^{a}$ & 14.43 & $100.0 \mathrm{a}$ & 0.00 & 1 & $65.0 a$ & 13.23 & $49.3 a b$ & 4.04 & 5 & Susceptible \\
\hline Regent & $8.3 \mathrm{~cd}$ & 2.89 & $54.0 \mathrm{bcd}$ & 2.00 & 5 & $8.3 c$ & 2.89 & 25.0de & 0.00 & 9 & DM_PM \\
\hline 3_016 & $5.0 d$ & 0.00 & 52.0bcde & 0.00 & 5 & $0.0 d$ & 0.00 & 2.3ij & 2.52 & 9 & DM \\
\hline 3_025 & not data & not data & not data & not data & not data & $25.0 b$ & 0.00 & 13.6fgh & $321 \%$ & 9 & DM \\
\hline 3_032 & $5.0 d$ & 0.00 & 36.3fghi & 3.51 & 7 & $5.0 \mathrm{~cd}$ & 0.00 & $21.6 \mathrm{ef}$ & 5.77 & 9 & DM \\
\hline 3_052 & 46.6ab & 20.21 & $100.0 \mathrm{a}$ & 0.00 & 1 & $5.0 \mathrm{~cd}$ & 0.00 & 5.Ohij & 0.00 & 9 & PM \\
\hline 3_058 & $30.0 \mathrm{bc}$ & 5.00 & $100.0 \mathrm{a}$ & 0.00 & 1 & $0.0 d$ & 0.00 & $0.0 \mathrm{j}$ & 0.00 & 9 & PM \\
\hline 3_070 & 50.0ab & 25.00 & $100.0 \mathrm{a}$ & 0.00 & 1 & $5.0 \mathrm{~cd}$ & 0.00 & 12.6fghi & 2.52 & 9 & PM \\
\hline 3_073 & 48.3ab & 37.86 & $100.0 \mathrm{a}$ & 0.00 & 1 & $5.0 \mathrm{~cd}$ & 0.00 & $1.6 \mathrm{j}$ & 2.89 & 9 & PM \\
\hline 3_082 & $5.0 d$ & 0.00 & 45.6cdef & 2.08 & 7 & $25.0 b$ & 0.00 & 45.0ab & 18.03 & 5 & DM \\
\hline 3_094 & $63.3 a$ & 12.58 & $100.0 \mathrm{a}$ & 0.00 & 1 & $5.0 \mathrm{~cd}$ & 0.00 & $0.0 \mathrm{j}$ & 0.00 & 9 & PM \\
\hline 4_001 & $48.3 a b$ & 37.86 & 100.0a & 0.00 & 1 & $25.0 b$ & 0.00 & $33.3 \mathrm{~cd}$ & 14.43 & 7 & PM \\
\hline 4_005 & $66.67 a$ & 14.43 & 100.0a & 0.00 & 1 & $5.0 \mathrm{~cd}$ & 0.00 & $0.0 \mathrm{j}$ & 0.00 & 9 & PM \\
\hline 4_011 & $50.0 \mathrm{ab}$ & 25.00 & 100.0a & 0.00 & 1 & $5.0 \mathrm{~cd}$ & 0.00 & $1.6 j$ & 2.89 & 9 & PM \\
\hline 4_032 & $11.6 \mathrm{~cd}$ & 11.55 & 40.0defg & 0.00 & 7 & $5.0 \mathrm{~cd}$ & 0.00 & 28.0de & 5.20 & 7 & DM \\
\hline 4_037 & $55.0 a$ & 8.66 & 100.0a & 0.00 & 1 & $5.0 \mathrm{~cd}$ & 0.00 & 9.3ghij & 4.04 & 9 & PM \\
\hline 4_063 & $5.0 d$ & 0.00 & 23.3ij & 9.87 & 9 & $25.0 b$ & 0.00 & 40.0bc & 15.00 & 5 & DM \\
\hline 4_082 & $5.0 d$ & 0.00 & 20.0jk & 0.00 & 9 & $5.0 \mathrm{~cd}$ & 0.00 & 6.6ghij & 2.89 & 9 & DM \\
\hline 4_124 & $11.6 \mathrm{~cd}$ & 11.55 & $65.0 \mathrm{~b}$ & 17.32 & 3 & $25.0 b$ & 0.00 & 40.0bc & 15.00 & 5 & DM \\
\hline 4_136 & 50.0ab & 25.00 & $100.0 \mathrm{a}$ & 0.00 & 1 & $5.0 \mathrm{~cd}$ & 0.00 & 17.3efg & 5.86 & 9 & DM_PM \\
\hline 5_022 & $18.3 \mathrm{~cd}$ & 11.55 & 25.6hij & 18.01 & 9 & $5.0 \mathrm{~cd}$ & 0.00 & $1.6 \mathrm{j}$ & 2.89 & 9 & DM_PM \\
\hline 5_033 & $5.0 d$ & 0.00 & 44.3cdef & 12.01 & 7 & $5.0 \mathrm{~cd}$ & 0.00 & 23.3def & 7.64 & 9 & DM_PM \\
\hline 5_060 & $5.0 d$ & 0.00 & 38.9efgh & 10.65 & 7 & $65.0 a$ & 13.23 & $53.3 a^{*}$ & 5.77 & 3 & DM \\
\hline 5_078 & $5.0 d$ & 0.00 & 20.0jk & 4.00 & 9 & $5.0 \mathrm{~cd}$ & 0.00 & 10.0ghij & 0.00 & 9 & PM \\
\hline 5_107 & $5.0 d$ & 0.00 & 30.0ghij & 0.00 & 9 & $1.6 \mathrm{~d}$ & 0.00 & $0.0 \mathrm{j}$ & 0.00 & 9 & DM_PM \\
\hline 6_018 & $5.0 d$ & 0.00 & $55.6 \mathrm{bc}$ & 25.58 & 5 & $5.0 \mathrm{~cd}$ & 0.00 & $21.6 \mathrm{ef}$ & 2.89 & 9 & DM_PM \\
\hline 6_025 & $5.0 d$ & 0.00 & $55.3 b c$ & 21.57 & 5 & $5.0 \mathrm{~cd}$ & 0.00 & 7.5ghij & 3.54 & 9 & DM_PM \\
\hline 6_046 & $11.6 \mathrm{~cd}$ & 11.55 & 40.3defg & 4.51 & 7 & $5.0 \mathrm{~cd}$ & 0.00 & 6.6ghij & 2.89 & 9 & DM_PM \\
\hline 6_080 & $5.0 d$ & 0.00 & $8.6 \mathrm{k}$ & 4.16 & 9 & $5.0 \mathrm{~cd}$ & 0.00 & 3.Ohij & 1.73 & 9 & DM_PM \\
\hline 6_125 & $11.0 \mathrm{~cd}$ & 12.17 & $51.3 \mathrm{bcde}$ & 1.15 & 5 & $5.0 \mathrm{~cd}$ & 0.00 & $1.6 j$ & 2.89 & 9 & DM_PM \\
\hline LSD (0.05) & 24.49 & & 14.15 & & & 5.71 & & 2.95 & & & \\
\hline
\end{tabular}

S.D., standard deviation. ${ }^{a}$ Means with the same letter are not significantly different (LSD test).

${ }^{*}$ Result for resistance based on the molecular findings: PM, Powdery mildew resistant; DM, Downy mildew resistant; PM_DM, Powdery and downy midew resistant.

UDV108_238 bp, and GF18-8_392 bp and the actual phenotypic resistance shown to downy mildew. Of the 16 genotypes (3_016, 3_032, 3_082, 4_032, 4_063, 4_082, 5_022, 5_033, 5_060, 5_078, 5_107, 6_018, 6_025, 6_046, 6_080, and 6_125) with resistance equal to or greater than that shown by "Regent" (OIV 452-1 =9, 7, and 5), 15 (all genotypes except for 5_078) possessed all four alleles (Supplementary Table 3). Genotype 5_078 gave a false negative result for resistance based on the molecular findings (Table 1). Of the 11 genotypes (3_052, 3_058, 3_070, 3_073, 3_082, 3_094, 4_001, 4_005, 4_011, 4_032, 4_037, 4_063, 4_082, 4_124, and 4_136) showing less resistance than "Regent" (OIV 452-1 = 1 and 3), nine (all genotypes except for 4_124 and 4_136) did not have all the above alleles (Supplementary Table 3). Genotypes 4_124 and 4_136 gave false positive results for resistance based on molecular findings (Table 1). The carriage of all four alleles was significantly associated $\left(\chi^{2}=19.57, p \leq 0.001\right)$ with actual phenotypic resistance.

\section{Ren3}

Supplementary Table 4 also shows the association between detection of the SSR alleles GF15-42_199 bp, GF15-28_341 bp, GF15-30_446 bp, and VChr15CenGen06_283 bp and actual phenotypic resistance shown to powdery mildew. Of the 24 genotypes (3_016, 3_025, 3_032, 3_052, 3_058, 3_070, 3_073, 3_094, 4_001, 4_005, 4_011, 4_032, 4_037, 4_082, 4_136, 5_022, 5_033, 5_078, 5_107, 6_018, 6_025, 6_046, 6_080, and 6_125) with resistance similar to "Regent" (OIV 455$1=7$ and 9), 19 (all genotypes except 3_016, 3_025, 3_032, 4_032 and 4_082) carried all four alleles (Supplementary Table 3). Genotypes 3_016; 3_025; 3_032; 4_032; 4_082 gave false negative results based on molecular findings (Table 1). The four genotypes (3_082, 4_063, 4_124 and 5_060) that showed actual phenotypic resistance well below that shown by "Regent" (OIV 455-1 = 1, 3 or 5) did not carry all four alleles (Supplementary Table 3 ). The carriage of all four alleles was 


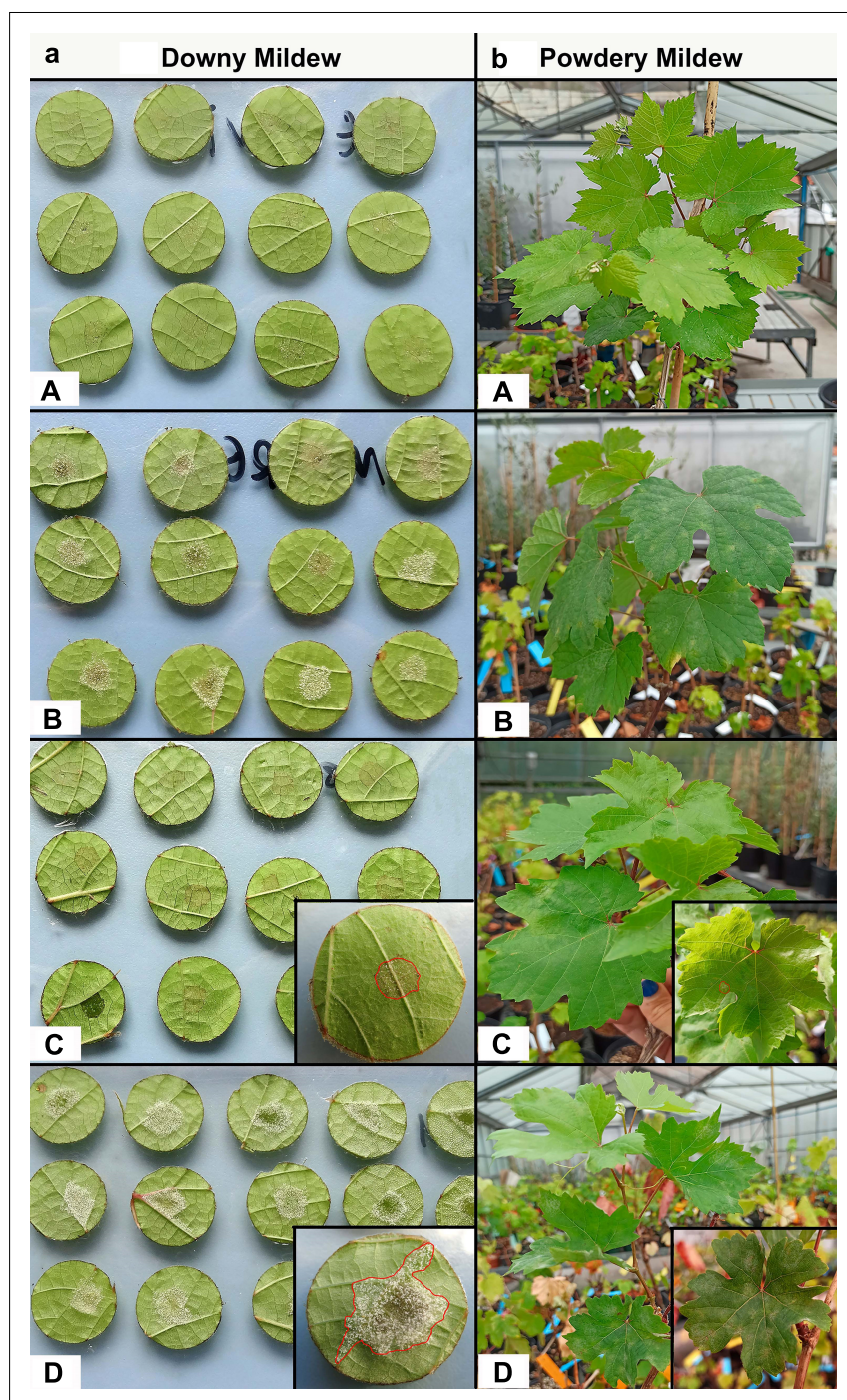

FIGURE 1 | (a) Images of leaf discs from genotypes showing different degrees of resistance to downy mildew (6 dpi), as well as greater resistance than "Regent" (no sporulation) or greater susceptibility than "Monastrell" (white downy mildew sporulation on the abaxial surface of leaf discs). (A) "Regent"; (B) "Monastrell"; (C) genotype 6_080 (resistant); (D) genotype 4_001 (susceptible). (b) Images of plants, grown under glasshouse conditions, belonging to genotypes showing different degrees of resistance to powdery mildew (6 dpi). (A) "Regent"; (B) "Monastrell"; (C) genotype 5_107 (resistant); (D) 5_060 (susceptible).

significantly associated $\left(\chi^{2}=10.70, p \leq 0.025\right)$ with actual phenotypic resistance.

\section{DISCUSSION}

The present leaf disc and plant inoculation results for resistance are reminiscent of those reported by other authors (Staudt and Kassemeyer, 1995; Prajongjai et al., 2014; Vezzulli et al., 2017) who indicate that non-vinifera hybrids are not fully resistant to downy and powdery mildew, and that the degree of resistance is a segregable trait. Indeed, in the present work, different degrees of resistance/susceptibility were seen among those genotypes generally classified as resistant or susceptible (Table 1). The greatest resistance to downy mildew was shown by genotypes $6 \_080$ and $4 \_082$, while $4 \_005$ showed the greatest susceptibility. With respect to powdery mildew, genotypes 3_058 and 5_107 showed the greatest resistance, while 5_060 showed the greatest susceptibility. The present data support the idea that transgressive segregation is common in plant breeding populations, with a number of recombinants appearing as outliers with respect to the resistance shown by the parental phenotypes (Mackay et al., 2021). With regard to downy mildew descriptor code OIV 452-1, 12 genotypes were transgressive with respect to the resistance donor "Regent" (OIV $=5)$, showing greater resistance than that genotype (OIV $=7$ or 9). Similar results were obtained by Vezzulli et al. (2019) in a segregating population for resistance to downy mildew. These extreme phenotypes suggest the presence of unidentified resistance factors that segregate in the breeding populations and result in minor but significant effects. The causes of transgressive segregation may be genetic (positive or negative complementation of additive alleles, epistatic interactions of unique parental attributes, the unmasking of recessive alleles from a heterozygous parent, or any combinations of these mechanisms) or environmental.

Zanghelini et al. (2019) agree with the present hyopthesis that a more environmentally friendly way to control grapevine disease would be to select new genotypes with combinations of resistance loci. In the present work, genotypes 6_080, 5_107 and 4_082 showed the greatest resistance to both downy and powdery mildew, and indeed these genotypes have been selected as the best progenitors in an IMIDA breeding program with the aim of combining their characteristics with those conferred by other resistance loci to downy mildew (e.g., Rpv10) and powdery mildew (e.g., Ren1), and thus help maintain the durability of resistance (pyramiding) (Eibach et al., 2007).

The possession of alleles of the SSRs used as markers of resistance was significantly associated with the actual phenotypic resistance to downy (especially) and powdery mildew, confirming that these markers can be used in plant improvement programmes designed to reduce the current use of pesticides. With respect to downy mildew, only two false positives were obtained (by genotypes 4_124 and 4_136, i.e., they were supposedly resistant but actually susceptible), and one false negative (by genotype 5_078, i.e., supposedly susceptible but actually showed resistance). With respect to powdery mildew, five false negative results were noted (provided by genotypes 3_016, 3_025, 3_032, 4_032, and 4_082. The additional fine mapping of the areas of the genome where different $R$-loci have been identified might provide more robust markers for use in marker-assisted selection (Zini et al., 2019; Zendler et al., 2021). Overall, these results confirm that MAS can be of great use in traditional improvement programmes, allowing for the selection of material with resistance to disease. However, MAS is not always as efficient as expected, possibly due to a relatively loose association between QTL alleles and the level of infection (Hospital, 2009). 
The introduction of resistance genes from Vitis species into a $V$. vinifera variety is a long and costly process, and in any event resistance may be overcome by particularly virulent pathogens. This is why the durability of resistance is crucial - particularly in the case of a perennial species like the vine. Plants that combine several resistance factors might be expected to show greater durability of resistance, even if they display the same level of resistance as those bearing only one resistance factor. MAS can be used to identify those genotypes that combine desired resistance factors, thus helping in the generation of varieties of greater potential for resistance durability. However, it does not appear to be so useful in identifying small-effect loci that can enhance the protection conferred by major genes and thus improve their durability (Merdinoglu et al., 2018). Hence the importance of combining MAS with phenotypic characterisation; this should allow for the better determination of the degree of resistance. Breeding programs should be vigilant of any advances made in molecular biology and genomic selection that might help construct varieties with highly durable resistance (Meuwissen et al., 2001; Merdinoglu et al., 2018).

In conclusion, cross-breeding programs generate great variation and allow for the selection of new genotypes that can promote a more sustainable and environmentally friendly form of viticulture - as long as the winemaking quality of their grapes is confirmed. This variation may include extreme phenotypes that show greater resistance than the actual donor. The combination of phenotypic characterisation and molecular selection is very useful, allowing the degree of resistance achieved in new genotypes, and the durability of that resistance, to be more accurately determined. The very resistant lines discussed in the present work provide valuable material for obtaining durably resistant genotypes, and should help characterise the molecular basis of resistance to downy and powdery mildew.

\section{DATA AVAILABILITY STATEMENT}

The original contributions presented in the study are included in the article/Supplementary Material, further inquiries can be directed to the corresponding author.

\section{AUTHOR CONTRIBUTIONS}

LR-G, SB, and MM proposed the study, planned and directed it, set goals, undertook experimental work, analysed and interpreted the results, and wrote the draft of the manuscript. JS helped to wrote the draft of the manuscript. PG and CM-M undertook experimental work and helped to wrote the draft of the manuscript. DF-L undertook experimental work. All authors

\section{REFERENCES}

Armijo, G., Schlechter, R., Agurto, M., Munoz, D., Nunez, C., and Arce-Johnson, P. (2016). Grapevine pathogenic microorganisms: understanding infection contributed to the final version and read and approved the final manuscript.

\section{FUNDING}

This work was financed by the European Regional Development Fund (80\%) through Projects PO07-037, FEDER1420-04, and FEDER1420-29, with the collaboration of the Region of Murcia (20\%).

\section{ACKNOWLEDGMENTS}

The authors thank Iván González, Elena Zubiaurre, and Ana Fuentes-Denia for technical assistance and Sergio LucasMiñano, Adrián Yepes-Hita, and José Antonio MartínezJiménez for plant management in the field. PCR products were separated by capillary electrophoresis in an ABI Prism 3730 sequencer at the Unidad de Genómica-Universidad Complutense de Madrid/Parque Científico de Madrid, Spain. The English manuscript was prepared by Adrian Burton (www.physicalevidence.es).

\section{SUPPLEMENTARY MATERIAL}

The Supplementary Material for this article can be found online at: https://www.frontiersin.org/articles/10.3389/fpls.2021. 674510/full\#supplementary-material

Supplementary Figure 1 | Resistance to downy mildew as recorded by OIV 452-1 descriptors (leaf discs inoculated with P. viticola sporangia). The scores for resistance to downy mildew were: OIV-1, very low resistance (dense sporulation over large lesions, $100 \%$ of discs affected); OIV-3, low resistance (dense sporulation over medium-sized lesions, 65-99\% of discs affected; OIV-5, medium resistance (little sporulation over small-mid size lesions, $47-64 \%$ of discs affected; OIV-7, strong resistance (scant sporulation over small lesions; $31-46 \%$ of discs affected); OIV-9, very strong resistance (scant sporulation over small lesions; $<30 \%$ of discs affected).

Supplementary Figure 2 | Resistance to powdery mildew as recorded by descriptor OIV 455-1 (leaf in glasshouse inoculated with E. necator). The scores for resistance to powdery mildew were: 1 , very low resistance [dense sporulation over the entire leaf surface (Adaxial) (estimating an average for all leaves)], $>75$ of plants affected); 3, low resistance (dense sporulation over 65-100\%, 50-75\% of plants affected); 5, medium resistance (sporulation over 25-65\%, $36-50 \%$ of plants affected); 7 , strong resistance (scant sporulation over 5-25, $25-35 \%$ of plants affected); 9 , very strong resistance (sporulation over $\leq 5 \%,<25 \%$ plants affected).

Supplementary Figure 3 | Relationship between disease incidence and severity for downy (leaf disc test) and powdery (glasshouse observation) mildew. Alleles of $\mathrm{DMR}=\mathrm{SSR}$ alleles associated with resistance to downy mildew (all four alleles present). Alleles of PMR = SSR alleles associated with resistance to downy mildew (all four alleles present). DM_PM resistant to downy and powdery mildew.

strategies and host response scenarios. Front. Plant Sci. 7:382. doi: 10.3389/ fpls.2016.00382

Bayo-Canha, A., Costantini, L., Fernandez-Fernandez, J. I., Martinez-Cutillas, A., and Ruiz-Garcia, L. (2019). QTLs related to berry acidity identified in a wine 
grapevine population grown in warm weather. Plant Mol. Biol. Rep. 2019:11456. doi: 10.1007/s11105-019-01145-6

Bellin, D., Peressotti, E., Merdinoglu, D., Wiedemann-Merdinoglu, S., AdamBlondon, A. F., Cipriani, G., et al. (2009). Resistance to Plasmopara viticola in grapevine 'Bianca' is controlled by a major dominant gene causing localised necrosis at the infection site. Theor. Appl. Genet. 120, 163-176. doi: 10.1007/ s00122-009-1167-2

Boso, S., Martinez, M. C., Unger, S., and Kassemeyer, H.-H. (2006). Evaluation of foliar resistance to downy mildew in different cv. Albariño clones. Vitis 4, 23-27.

Boso, S., Alonso-Villaverde, V., Santiago, J. L., Gago, P., Dürrenberg, M., Duggelin, M., et al. (2010). Macro- and microscopic leaf characteristics of six grapevine genotypes (Vitis spp.) with different susceptibilities to grapevine downy mildew. Vitis 49, 43-50.

Boso, S., Alonso-Villaverde, V., Gago, P., Santiago, J. L., and Martínez, M. C. (2014). Susceptibility to downy mildew (Plasmopara viticola) of different Vitis varieties. Crop Prot. 63, 26-35. doi: 10.1016/j.cropro.2014.04.018

Bove, F., Savary, S., Willocquet, L., and Rossi, V. (2020). Designing a modelling structure for the grapevine downy mildew pathosystem. Eur. J. Plant Pathol. 157, 251-268. doi: 10.1007/s10658-020-01974-2

Brown, M. V., Moore, J. N., Fenn, P., and McNew, R. W. (1999). Comparison of leaf disk, greenhouse, and field screening procedures for evaluation of grape seedlings for downy mildew resistance. HortScience 34, 331-333. doi: 10.21273/ HORTSCI.34.2.331

Casagrande, K., Falginella, L., Castellarin, S. D., Testolin, R., and Di Gaspero, G. (2011). Defence responses in Rpv3-dependent resistance to grapevine downy mildew. Planta 234, 1097-1109. doi: 10.1007/s00425-011-1461-5

Di Gaspero, G., Cipriani, G., Marrazzo, M. T., Andreetta, D., Prado Castro, M. J., Peterlunger, E., et al. (2005). Isolation of (AC)n-microsatellites in Vitis vinifera L. and analysis of genetic background in grapevines under marker assisted selection. Mol. Breed. 15, 11-20. doi: 10.1007/s11032-004-1362-4

Di Gaspero, G., Copetti, D., Coleman, C., Castellarin, S. D., Eibach, R., Kozma, P., et al. (2012). Selective sweep at the Rpv3 locus during grapevine breeding for downy mildew resistance. Theor. Appl. Genet. 124, 277-286. doi: 10.1007/ s00122-011-1703-8

Eibach, R., Zyprian, E., Welter, L., and Töpfer, R. (2007). The use of molecular markers for pyramiding resistance genes in grapevine breeding. Vitis 46,120 124.

Fischer, B. M., Salakhutdinov, I., Akkurt, M., Eibach, R., Edwards, K. J., Töpfer, R., et al. (2004). Quantitative trait locus analysis of fungal disease resistance factors on a molecular map of grapevine. Theor. Appl. Genet. 108, 501-515. doi: 10.1007/s00122-003-1445-3

Gessler, C., Pertot, I., and Perazzolli, M. (2011). Plasmopara viticola: a review of knowledge on downy mildew of grapevine and effective disease management. Phytopathol. Mediterr. 50, 3-44.

Hoffmann, S., Di Gaspero, G., Kovacs, L., Howard, S., Kiss, E., Galbacs, Z., et al. (2008). Resistance to Erysiphe necator in the grapevine 'Kishmish vatkana' is controlled by a single locus through restriction of hyphal growth. Theor. Appl. Genet. 116, 427-438. doi: 10.1007/s00122-0070680-4

Hospital, F. (2009). Challenges for effective marker-assisted selection in plants. Genetica 136, 303-310. doi: 10.1007/s10709-008 9307-1

Kozma, P., Kiss, E., Hoffmann, S., Galbacs, Z., and Dula, T. (2009). Using the powdery mildew resistant Muscadinia rotundifolia and Vitis vinifera 'Kishmish vatkana' for breeding new cultivars. Acta Hortic. 827, 559-564. doi: 10.17660/ ActaHortic.2009.827.97

Mackay, I. J., Cockram, J., Howell, P., and Powell, W. (2021). Understanding the classics: the unifying concepts of transgressive segregation, inbreeding depression and heterosis and their central relevance for crop breeding. Plant Biotechnol. J. 19, 26-34. doi: 10.1111/pbi. 13481

Maul, E., and Töpfer, R. (2019). VIVC-Vitis International Variety Catalogue. Available online at: http://www.vivc.de/ (accessed on May 31, 2019)

Merdinoglu, D., Schneider, C., Prado, E., Wiedemann-Merdinoglu, S., and Mestre, P. (2018). Breeding for durable resistance to downy and powdery mildew in grapevine. OENO One 52, 203-209. doi: 10.20870/oeno-one.2018.52.3. 2116
Meuwissen, T. H. E., Hayes, B. J., and Goddard, M. E. (2001). Prediction of total genetic value using genome-wide dense marker maps. Genetics 157, 1819-1829. doi: 10.1093/genetics/157.4.1819

Organisation Internationale de la Vigne et du Vin [OIV] (2009). Code des caractères descriptifs des variétés et espèces de Vitis. Deuxième édition. Paris: Dedon. 232.

Possamai, T., Migliaro, D., Gardiman, M., Velasco, R., and De Nardi, B. (2020). Rpv mediated defense responses in grapevine offspring resistant to Plasmopara viticola. Plants 9:781. doi: 10.3390/plants906 0781

Prajongjai, T., Poolsawat, O., Pornbungkerd, P., Wongkaew, S., and Tantasawat, P. A. (2014). Evaluation of grapevines for resistance to downy mildew (Plasmopara viticola) under laboratory and field conditions S. Afr. J. Enol. Viticult. 35, 43-50. doi: 10.21548/35-1-983

Ruiz-García, L., Fuentes, A., García, B., Martínez, J. A., and MartínezCutillas, A. (2014). Selection of new fungal disease resistant grapevine varieties generated by crosses involving Monastrell. Proceedings of the $7^{\text {th }}$ International Workshop on Grapevine Downy and Powdery Mildew. Vitoria. $155-156$.

Rumbolz, J., Wirtz, S., Kassemeyer, H.-H., Guggenheim, R., Schäfer, E., and Büche, C. (2002). Sporulation of Plasmopara viticola: differentiation and light regulation. Plant Biol. 4, 413-422. doi: 10.1055/s-200232342

Staudt, G., and Kassemeyer, H. (1995). Evaluation of downy mildew resistance in various accessions of wild Vitis species. Vitis 34, 225-228.

Töpfer, R., Hausmann, L., and Eibach, R. (2011). "Molecular breeding," in Genetics, genomics, and breeding of grapes, eds A.-F. Adam-Blondon, J.-M. MartinezZapater, and C. Kole (Boca Raton: CRC Press), 160-185. doi: 10.1201/b1 0948

Van Heerden, C. J., Phyllis, B., Abraham, V., and Renée, P. (2014). Detection of downy and powdery mildew resistance QTL in a 'Regent' $x$ 'RedGlobe' population. Euphytica 200, 281-295. doi: 10.1007/s10681-014-1167-4

Vezzulli, S., Vecchione, A., Stefanini, M., and Zulini, L. (2017). Downy mildew resistance evaluation in 28 grapevine hybrids promising for breeding programs in Trentino region (Italy). Eur. J. Plant Pathol. 150, 485-495. doi: 10.1007/ s10658-017-1298-2

Vezzulli, S., Malacarne, G., Masuero, D., Vecchione, A., Dolzani, C., Goremykin, V., et al. (2019). The Rpv3-3 haplotype and stilbenoid induction mediate downy mildew resistance in a grapevine interspecific population. Front. Plant Sci. 10:234. doi: $10.3389 /$ fpls.2019.00234

Villano, C., and Aversano, R. (2020). Towards grapevine (Vitis vinifera L.) mildews resistance: molecular defence mechanisms and new breeding technologies. Italus Hortus 27, 1-17. doi: 10.26353/j.itahort/2020.3.0117

Wan, Y., Schwaniniger, H., He, P., and Wang, Y. (2007). Comparison of resistance to powdery mildew and downy mildew in Chinese wild grapes. Vitis 2007, $132-136$.

Wang, Y., Li, Y., He, P., Chen, J., Lamikanra, O., and Lu, J. (1995). Evaluation of foliar resistance to Uncinula necator in Chinese wild Vitis species. Vitis 34, 159-164.

Welter, L. J., Göktürk-Baydar, N., Akkurt, M., Maul, E., Eibach, R., Töpfer, R., et al. (2007). Genetic mapping and localization of quantitative trait loci affecting fungal disease resistance and leaf morphology in grapevine (Vitis vinifera L). Mol. Breed. 20, 359-374. doi: 10.1007/s11032-007-9097-7

Zanghelini, J. A., Bogo, A., Dal Vesco, L. L., Gomes, B. R., Mecabo, C. V., Herpich, C. H., et al. (2019). Response of PIWI grapevine cultivars to downy mildew in highland region of southern Brazil. Eur. J. Plant Pathol. 154, 1051-1058. doi: 10.1007/s10658-019-01 725-y

Zendler, D., Schneider, P., Topfer, R., and Zyprian, E. (2017). Fine mapping of Ren3 reveals two loci mediating hypersensitive response against Erysiphe necator in grapevine. Euphytica 213:68. doi: 10.1007/s10681-0171857-9

Zendler, D., Topfer, R., and Zyprian, E. (2021). Confirmation and fine mapping of the resistance locus Ren 9 from the grapevine cultivar 'Regent'. Plants 2021:24. doi: 10.3390/plants10010024

Zini, E., Dolzani, C., Stefanini, M., Gratl, V., Bettinelli, P., Nicolini, D., et al. (2019). R-loci arrangement versus downy and powdery mildew resistance level: a Vitis hybrid survey. Int. J. Mol. Sci. 20:3526. doi: 10.3390/ijms2014 3526 
Zyprian, E., Ochßner, I., Schwander, F., Šimon, S., Hausmann, L., Bonow-Rex, M., et al. (2016). Quantitative trait loci affecting pathogen resistance and ripening of grapevines. Mol. Genet. Genom. 291, 1573-1594. doi: 10.1007/s00438-0161200-5

Conflict of Interest: The authors declare that the research was conducted in the absence of any commercial or financial relationships that could be construed as a potential conflict of interest.

Publisher's Note: All claims expressed in this article are solely those of the authors and do not necessarily represent those of their affiliated organizations, or those of the publisher, the editors and the reviewers. Any product that may be evaluated in this article, or claim that may be made by its manufacturer, is not guaranteed or endorsed by the publisher.

Copyright (c) 2021 Ruiz-García, Gago, Martínez-Mora, Santiago, Fernádez-López, Martínez and Boso. This is an open-access article distributed under the terms of the Creative Commons Attribution License (CC BY). The use, distribution or reproduction in other forums is permitted, provided the original author(s) and the copyright owner(s) are credited and that the original publication in this journal is cited, in accordance with accepted academic practice. No use, distribution or reproduction is permitted which does not comply with these terms. 